\title{
Thromboembolic Events in Patients Treated with Anti-Angiogenic Drugs
}

\author{
Patrizia Ferroni ${ }^{1, *}$, Vincenzo Formica ${ }^{2}$, Mario Roselli $^{2}$ and Fiorella Guadagni ${ }^{1}$
}

${ }^{1}$ Department of Laboratory Medicine \& Advanced Biotechnologies, IRCCS San Raffaele Pisana, Via della Pisana 235, 00163 Rome, Italy; ${ }^{2}$ Medical Oncology, Department of Internal Medicine, University of Rome “Tor Vergata”, Policlinico Tor Vergata, Viale Oxford 81, 00133 Rome, Italy

\begin{abstract}
Induction of neo-angiogenesis is a fundamental step in many pathological conditions. The therapeutic value of inhibiting angiogenesis is an interesting area of research in oncology, with vascular endothelial growth factor (VEGF) being the most suitable anti-angiogenic target. In the last decade a number of anti-VEGF drugs have demonstrated, especially in combination with standard chemotherapy, clinical efficacy in the treatment of different solid tumor types. As data from clinical trials on anti-VEGF drugs are becoming available, it is increasingly recognized that VEGF, in addition to being a permeability, proliferation, and migration factor, is also a maintenance and protection factor for endothelial cells, being capable of regulating multiple biological functions, i.e. the production of vasoactive mediators and the expression of components of the thrombolytic and coagulation pathways. Consequently, the disturbance of vascular homeostasis by blocking VEGF may lead to endothelial dysfunction and adverse vascular effects, such as venous and arterial thromboembolic events. In preclinical models angiogenesis and the increased expression of VEGF has been associated to altered expression of proinflammatory genes. These genes may be regulated in a biphasic manner, and it is possible that anti-VEGF therapy may disrupt a negative feedback loop that leads to potential in situ thrombus formation. Accordingly, combination treatment with bevacizumab and chemotherapy, compared with chemotherapy alone, was recently associated with an increased risk of thromboembolism.
\end{abstract}

The present review considers the biological mechanisms and clinical impact of thromboembolic complications during anti-angiogenic treatments in cancer patients.

Keywords: Vascular endothelial growth factor, oxidant stress, nitric oxide, bevacizumab, endothelial dysfunction, haemostatic activation.

\section{BIOLOGICAL PROPERTIES OF THE ENDOTHE- LIUM}

The endothelium is a dynamic organ that plays a critical role in maintaining vascular homeostasis. The endothelial cell (EC), in fact, behaves as a receptor-effector structure which senses different physical or chemical stimuli that occur inside the vessel and, therefore, modifies the vessel shape or releases the mediators to counteract the effect of the stimulus and maintain homeostasis. The net effect is maintenance of normal vascular tone, but the endothelium also maintains normal blood viscosity, prevents abnormal blood clotting, and prevents abnormal bleeding in terms of a balance between tissue plasminogen activator and its inhibitor. In addition, it limits inflammation of the vasculature and it can suppress smooth muscle cell proliferation. These are functions of the normal endothelium. The opposite occurs in the presence of a dysfunctional endothelium, in which abnormally functioning ECs cause vasoconstriction, increased inflammation and thrombosis (Fig. (1)) [1].

Our increased understanding of the endothelium's role began in the early eighties with the studies carried out by the Nobel Prize winner Furchgott, who hypothesized that the EC

\footnotetext{
*Address correspondence to this author at the Department of Laboratory Medicine \& Advanced Biotechnologies, IRCCS San Raffaele Pisana, Via della Pisana 235, 00163 Rome, Italy; Tel: +39 (06) 66130425; Fax: +39 (06) 66130407; E-mail: patrizia.ferroni@sanraffaele.it
}

had an important role in smooth muscle relaxation [2]. The findings obtained in this pioneering work represented a considerable advance, because the causative compound called endothelial-derived relaxing factor (EDRF) had yet to be identified and, in fact, remained unidentified for years until its chemical structure was characterized as nitric oxide (NO).

NO is continuously synthesized by the endothelium and has a wide range of biological properties that maintain vascular homeostasis. It is a potent vasodilator and inhibitor of platelet aggregation and thus has an important protective role. Accordingly, endothelial dysfunction is generally regarded as a decreased NO bioavailability [3].

Oxidative stress also contributes to homeostasis in vascular cells [3]. Oxidant products [referred as reactive oxygen species (ROS)] are produced as a consequence of normal aerobic metabolism, but are highly reactive with other biological molecules. Under normal physiological conditions, ROS production is balanced by an efficient system of antioxidants, molecules that are capable of neutralizing them and thereby preventing oxidant damage. In pathological states, ROS may be present in relative excess and this shift of balance in favor of oxidation (oxidative stress) may have detrimental effects on cellular and tissue function [3, 4].

Several enzyme systems contribute to production of ROS in vascular tissues. Among them, the NO synthase (NOS), and in particular the endothelial isoform of NOS (eNOS) is now recognized as an important source of superoxide in sev- 
Activating stimulus

(cytokines, oxidant stress, etc.)

Dysfunctional endothelium
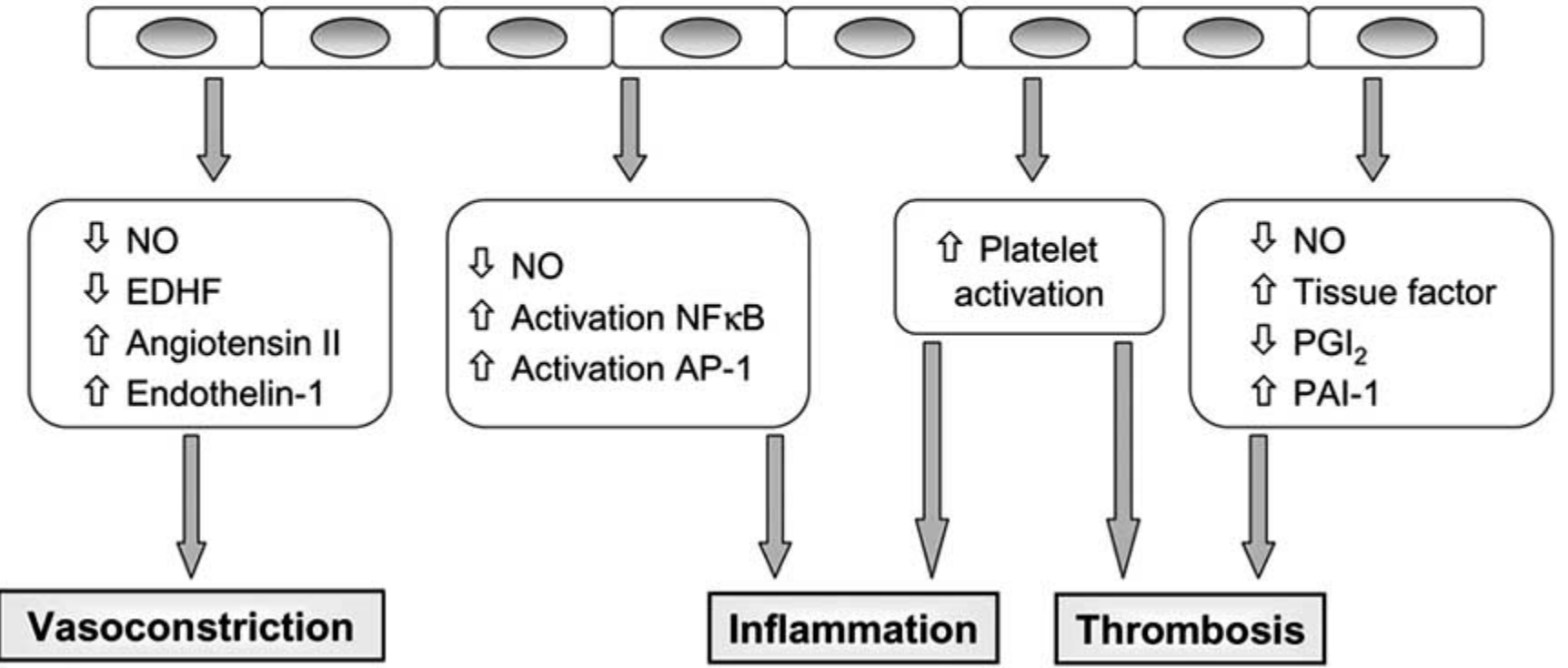

Fig. (1). An activating stimulus, such as cytokines, or a condition of increased oxidant stress, would lead to activation of endothelial cells (EC) and platelets, which causes a switch toward a pro-thrombotic, pro-inflammatory condition contributing to increased cardiovascular risk. EDHF: endothelium derived hyperpolarizing factor; NF- $\kappa B$ : nuclear transcription factor- $\kappa \mathrm{B}$; AP-1: activator protein-1; STATs: signal transducers and activators of transcription; $\mathrm{PGI}_{2}$ : prostacyclin; PAI-1: plasminogen activator inhibitor-1.

eral clinical settings [5]. Furthermore, eNOS can generate superoxide rather than $\mathrm{NO}$ in response to pathogenic stimuli. These findings have led to the concept of "NOS uncoupling", where the activity of the enzyme for NO production is decreased, in association with an increase in NOSdependent superoxide production, such that both superoxide and NO are produced simultaneously. Under this circumstance, eNOS may become a peroxynitrite generator, leading to a dramatic increase in oxidative stress, since peroxynitrite formed by the NO-superoxide reaction, has additional detrimental effects on vascular function [4].

Beside their direct attack to various cellular targets (i.e. nucleic acids, lipids, etc.), ROS are also capable of activating other signaling molecules, such as protein kinase $\mathrm{C}$ (PKC) and nuclear transcription factor- $\mathrm{KB}(\mathrm{NF}-\mathrm{\kappa B})$ leading to transcription of genes encoding cytokines, growth factors and adhesion molecules [6]. These molecular changes are ultimately responsible for the phenotypic switch of the endothelium from a non-adhesive, non-thrombogenic cellular interface to one that expresses and secretes several adhesion molecules and chemoattractants capable of recruit and activate other vascular cell types $[4,6]$.

In recent years it has become increasingly recognized that ROS can act as signaling molecules not only in the inflammatory response, but also in many aspects of growth factormediated physiological responses. In fact, at moderate, nontoxic concentrations, ROS act as physiological signal transduction messengers, and a variety of natural stimuli works by changing the cellular redox (oxidation/reduction) state as a part of the normal intracellular signaling network [7].

\section{VASCULAR ENDOTHELIAL GROWTH FACTOR (VEGF): ANGIOGENIC AND VASCULAR PROTEC- TIVE ACTIONS}

Recent reports suggest that ROS play an important role in angiogenesis [8]. The underlying molecular mechanism(s) remain largely unknown, but numerous reports have demonstrated that the intracellular redox state is closely associated with the pattern of VEGF expression [9-12].

\section{VEGFs and their Receptors}

Angiogenesis and lymphangiogenesis are regulated predominantly by several different growth factors and their associated receptor tyrosine kinases. Foremost among these is the VEGF family, which consists of several members, mainly VEGF-A, VEGF-B, VEGF-C and VEGF-D, sharing a common structure of 8 characteristically spaced cysteine residues in a VEGF homology domain [13]. VEGF-A (hereinafter referred to as VEGF), initially designated VPF (vascular permeability factor), is essential for angiogenesis in health and pathophysiology, and it is currently a major focus for drug targeting in the development of novel treatments for different human diseases [13-16]. Other members of this family might be involved in inflammatory angiogenesis (VEGF-B) [17], or may act as lymphangiogenic growth factors (VEGF-C and VEGF-D) [17, 18]. VEGF signal in arterial and venous ECs is transduced through 2 main receptors with tyrosine kinase activity, namely, VEGFR1 and VEGFR2 [19]. There is considerable evidence that VEGFR2 is the major mediator of VEGF-driven responses in endothelial cells and it is a crucial signal transducer in both 
physiologic and pathologic angiogenesis [20]. The VEGF gene has its expression regulated by ROS and additional data support the hypothesis that VEGF mRNA is up-regulated by hydrogen peroxide in a dose- and time-dependent manner $[21,22]$. Furthermore, hydrogen peroxide is also capable of inducing a significant VEGFR2 expression [23].

The binding of VEGF to 1 of its transmembrane tyrosine kinase receptors, which are predominantly found on endothelial cells, results in receptor dimerisation, activation and autophosphorylation of the tyrosine kinase domain. This triggers a cascade of complex downstream signaling pathways (Fig. (2)).

\section{VEGF SIGNALING IN ENDOTHELIAL CELL BIO- LOGY}

\section{Regulation of Vascular Permeability}

VEGF was originally identified as a factor which increased vascular permeability $[24,25]$. However, the signaling mechanisms underlying this effect remain largely unknown. Induction of endothelial fenestrations may be an important mechanism by which VEGF modulates vascular permeability [26]. The signaling pathways mediating VEGFinduced fenestration are unclear, though a permissive environment involving changes in the composition of the ex- tracellular matrix may be required [26, 27]. VEGF-induced formation of fenestrations is associated with caveolae. These are a subset of lipid raft domains seen as morphologically distinct, flask-shaped invaginations that are particularly abundant and critical in the cardiovascular system [28]. In vascular endothelial cells, caveolae represent approximately $95 \%$ of cell surface vesicles and have multiple functions in organizing and regulating signaling cascades, controlling cell motility, and serving as endocytic carriers [28].

VEGF also induces the appearance of vesicular-vacuolar organelles $[29,30]$ and the role for NO in mediating VEGFinduced vascular permeability is supported by the observations that the eNOS inhibitor L-NAME inhibited permeability changes induced by VEGF in vivo [31]. Furthermore, the close coupling between activated VEGFR2 and eNOS is brought about by their colocalization within caveolae/lipid rafts and direct associations with caveolin-1. The activation of caveolar eNOS depends on caveolin-1 dissociation [reviewed in 28]. In the absence of VEGFR2 activation, caveolin-1 tightly binds to a motif in the oxygenase domain of eNOS maintaining the enzyme in an inactive state within caveolae. VEGF stimulation leads to Src kinase-mediated phosphorylation of caveolin-1 [32]. Consequently, eNOS dissociates from caveolin-1 and becomes activated by binding to calmodulin, dynamin-2a, and several heat shock pro-

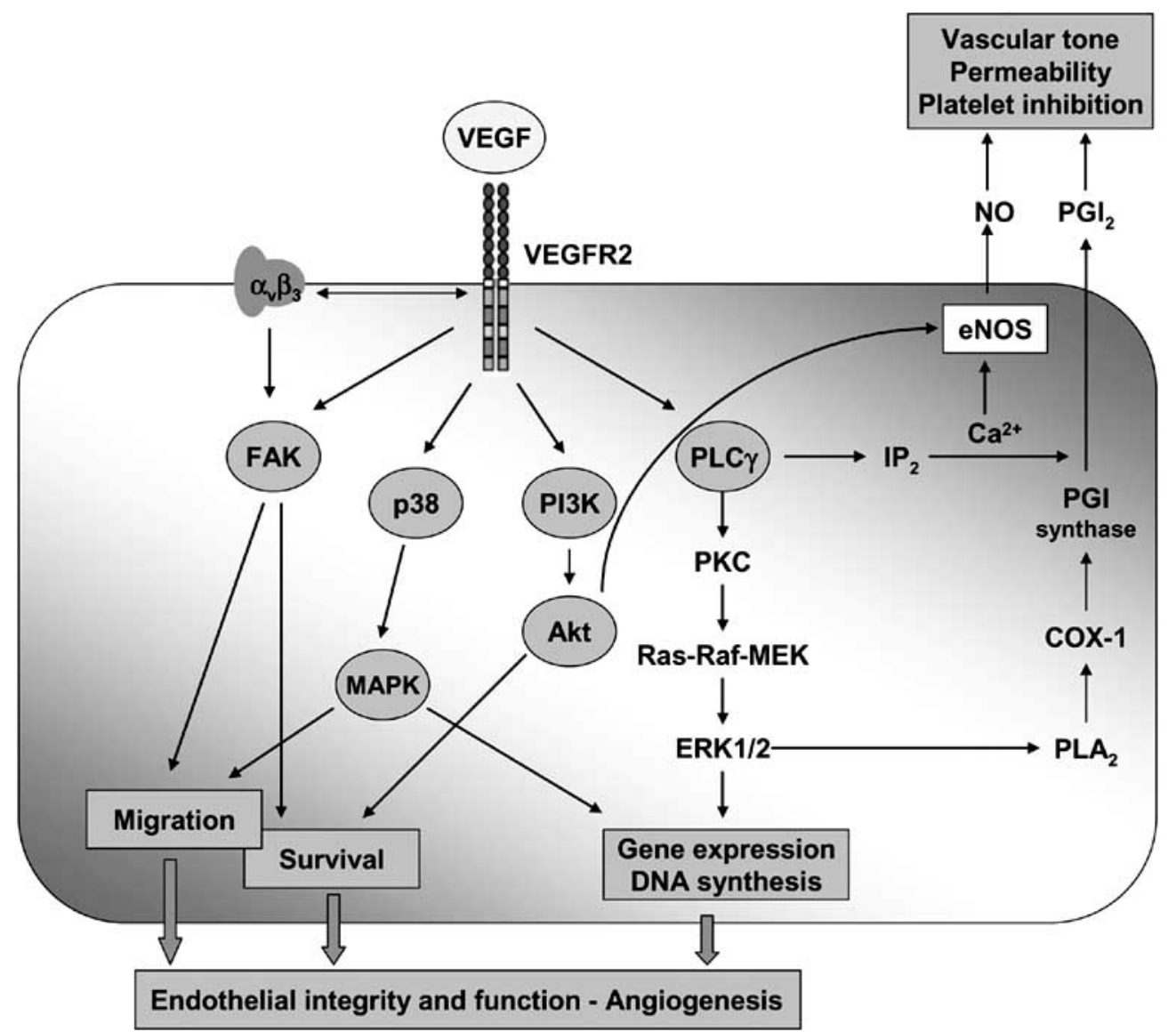

Fig. (2). Vascular endothelial growth factor (VEGF) signaling via its receptor (VEGFR2). VEGF binding to VEGFR2 initiates a number of signaling cascades leading to cell survival, migration, and proliferation of endothelial cells. NO: nitric oxide; $\mathrm{PGI}_{2}$ : prostacyclin; eNOS: endothelial NO synthase; PLC $\gamma$; PKC: protein kinase C; ERK: extracellular regulated kinase; MAPK: mitogen activated protein kinase; FAK: focal adhesion kinase; PI3-K: phosphatidylinositol 3' kinase; Akt/PKB: protein kinase B; COX-1: cyclooxygenase-1; PLA 2 : phospholipase-2. 
teins [33]. Taken together, the experimental data now available support a model in which endocytosis and trafficking contribute to the rapid and transient activation of eNOS. A detailed discussion of the events leading to internalization and recycling of VEGFR2 and NO is beyond the scope of this review and has been the objective of a recent article [28].

Other molecules have been implicated as effectors of VEGF-induced venular permeability, such as PLC- $\gamma$ tyrosine phosphorylation, mobilization of intracellular calcium and PKC activation [34]. VEGF increased phosphorylation of components of intercellular endothelial adherens and tight junctions may mediate disruption of cell-cell adhesions, leading to increased vasopermeability [35-37]. Nonetheless, some evidence has been published against the involvement of VEGFR2 in the ability of VEGF to trigger vascular permeability [38]. Thus, the issue is still an open matter.

\section{Cell Survival and Proliferation}

A fundamental cellular mechanism by which VEGF promotes the formation of new blood vessels and maintains their integrity is the activation of EC survival or antiapoptotic signaling [39]. Long-term effects of VEGF on EC survival are mediated through upregulation of components of the anti-apoptotic cellular machinery. VEGF, in fact, is capable of inhibiting apoptosis by several mechanisms, including activation of the anti-apoptotic kinase, Akt/PKB [22, 40, 41], induction of the antiapoptotic proteins $\mathrm{Bcl}-2$ and $\mathrm{A} 1$ [42] and upregulation of survivin and the X-chromosomelinked inhibitor of apoptosis (XIAP) [43]. VEGF also stimulates DNA synthesis and proliferation through the activation of extracellular-regulated kinase (ERK), which is mediated by Ras-Raf-MEK-ERK pathway [44, 45]. The mitogen activated protein kinase (MAPK) pathway is also implicated in cell proliferation in response to VEGF [46]. All these phenomena are mediated by VEGFR2 and VEGF binding to VEGFR1 is not involved in VEGF-mediated cell survival [22].

Other signaling pathways may also play a role in endothelial cell survival functions of VEGF. For example, integrins/cell adhesion receptors such as the endothelium specific adhesion molecule $\alpha v \beta 3$ also play a role in VEGF signal transduction. The cell adhesion molecule VE-Cadherin interacts with VEGFR2 forming a complex with $\beta$-catenin and PI3-Kinase to promote cell survival [47]. Surprisingly, the same part of VE-cadherin mediates effects that in one case support VEGFR2 signaling (antiapoptosis, survival effects) and in the other case inhibit VEGFR2 signaling (proliferative effects) [48]. Furthermore, it has been recently demonstrated that semaphorin (sema) 3C promotes EC survival and proliferation and stimulates cell adhesion, migration, and tube formation in vitro by inducing $\beta 1$ integrin serine phosphorylation and VEGF secretion via NP/plexin signaling [49].

VEGF-induced proliferation was reported to be dependent on a NO-mediated reduction PKC $\delta$ activity [50]. Notably, PKC $\delta$ transduces a principal signal for the upregulation of vasohibin, a negative regulator of angiogenesis genetically programmed in ECs [51]. Vasohibin is dominantly expressed in ECs, induced by the stimulation with VEGF or fibroblast growth factor-2 (FGF-2), and selectively affects on ECs and inhibits angiogenesis. However, the mechanism of how vasohibin inhibits angiogenesis remains to be elucidated [recently reviewed in 52].

\section{Cell Migration}

VEGF induces cell migration by increasing tyrosine phosphorylation and focal adhesion association of FAK (focal adhesion kinase) [53-55] and also via the PI3 Kinase/Akt pathway. FAK activation is mediated by the c-terminal region of VEGFR2 [56]. VEGF activation of the p38/MAPK stress pathway is also implicated in cell migration and p38 inhibitors decrease cell migration [57]. Using VEGF mutants it was determined that only VEGFR2 and not VEGFR1 resulted in p38 phosphorylation suggesting that VEGFR2 is the main mediator of cell migration in ECs [58].

Other mechanisms have been involved in EC migration. Among these, the capability of VEGF of inducing the expression of matrix-degrading metalloproteinases, which are likely to play an essential permissive role in VEGF-induced migration in vivo [59]. In addition, it has been suggested that NO production may play a role in VEGF-induced endothelial cell migration. It is well known that VEGF induces NO production and NO is implicated in non-chemotactic scalar movement (podokinesis) of ECs and as a permissive factor in VEGF-induced endothelial cell migration $[60,61]$ and angiogenesis $[62,63]$. NO has been reported to regulate focal adhesion integrity and FAK tyrosine phosphorylation in endothelial cells [61] and Akt-dependent phosphorylation of eNOS was shown to be required for VEGF-induced cell migration [64].

\section{NO and Prostacyclin ( PGI $_{2}$ ) Production}

As reported above, VEGF increases both eNOS expression and $\mathrm{NO}$ and $\mathrm{PGI}_{2}$ production by ECs [31, 65-69]. VEGF-induced $\mathrm{PGI}_{2}$ production results from PKC-mediated ERK activation and ERK-mediated phosphorylation and activation of phospholipase $\mathrm{A}_{2}\left(\mathrm{PLA}_{2}\right)$ [65], a pathway that is unaffected by inhibitors of eNOS, suggesting that VEGF signaling leading to $\mathrm{NO}$ and $\mathrm{PGI}_{2}$ generation bifurcates upstream of ERK [70, 71].

In common with other activators of eNOS, short-term NO production induced by VEGF probably involves calcium mobilization and activation of the constitutive isoform [71], but VEGF via activation of VEGFR2, is also capable of upregulating eNOS mRNA and protein expression [72-74] providing a mechanism for prolonged VEGF-induced NO production [71].

$\mathrm{NO}$ and $\mathrm{PGI}_{2}$ are best known as vasodilators, but they have several vascular protective effects, including antiplatelet actions, and in the case of NO, inhibition of leukocyte adhesion [71]. Accordingly, VEGF may have similar vascular protective effects through enhanced NO and PGI production [71]. Evidence that VEGF has NO-dependent vascular protective effects independent of angiogenesis or endothelial cell proliferation, comes from preclinical and clinical studies addressing the role of this cytokine in atherosclerosis and its complications [75, 76]. Moreover, an antithrombotic effect of VEGF may result both from NO and 
$\mathrm{PGI}_{2}$-mediated inhibition of platelet aggregation, and from VEGF-induced expression and activation of the serine proteases, urokinase and tissue type plasminogen activator [77], which cleave plasminogen to generate the key thrombolytic enzyme plasmin. As an apparent paradox, VEGF also has potentially pro-thrombogenic effects, including the induction of endothelial von Willebrand factor (vWF) secretion [71, 78], which is not only essential for platelet adhesion to subendothelial collagen, but increases also endothelial cell adhesion, thus cooperating in the maintenance of endothelial integrity [25].

\section{Vascular Protective Roles of VEGF in the Cardiovascu- lar System}

Increasing understanding of the multiplicity of actions exerted by VEGF has provided new insights in the comprehension of the vascular protective role of VEGF [10, 11] and might help to unravel the molecular mechanisms underlying vascular complications observed in patients using treatments that inhibit the VEGF signaling pathway. Although it is not yet fully elucidated how angiogenesis inhibitors upset normal hemostasis, it is likely that disruption of the function and/or integrity of vascular endothelium may lead to an increased risk for thrombosis and/or hemorrhage [79, 80].

In this context, the capability of VEGF of increasing NO production by ECs is of particular significance, considering that endothelial dysfunction is generally regarded as a decreased NO bioavailability and increased oxidative stress. Of particular interest are the findings by González-Pacheco et al. who suggested that, while high concentrations of hydrogen peroxide elicit clear-cut damaging effects, mild oxidative stress might act as a protective mechanism in ECs [23]. These effects involved significant changes in VEGF and VEGFR2 gene expression, the latter being mainly driven through a nuclear factor $\kappa \mathrm{B}(\mathrm{NF}-\kappa \mathrm{B})$-dependent pathway [23]. In addition, the cytoprotective effect exerted by low doses of hydrogen peroxide was shifted to an EC-damaging pattern by means of specific VEGF blockade, therefore revealing a major role of autologous VEGF and leading the authors to hypothesize that autocrine VEGF makes ECs more resistant to injury by oxidative agents [23]. Thus, one could postulate that the increased rate of thrombotic events observed in trials of combined anti-VEGF chemotherapeutic protocols might result from the blockade of such cytoprotective effect, which is even more crucial considering the increased oxidative stress $[81,82]$ and haemostatic activation [83] generally associated to chemotherapy.

Predisposition to thrombosis after inhibition of VEGF signaling may, indeed, reflect the multiplicity of actions of VEGF on vascular walls and perhaps on components of the coagulation system. VEGF not only stimulates endothelial cell proliferation, but also promotes ECs survival and helps maintain vascular integrity [84]. Inhibition of VEGF could thereby diminish the regenerative capacity of ECs and cause defects that expose pro-coagulant phospholipids on the luminal plasma membrane or underlying matrix, leading to thrombosis or haemorrhage [85]. In addition, the loss of antiplatelet activity due to reduced $\mathrm{NO}$ and $\mathrm{PGI}_{2}$ after inhibition of VEGF signaling may predispose to thromboembolic events.
Although the prevailing rationale for thrombosis in antiangiogenic therapies is that VEGF blockade leads to vascular inflammation and clotting, yet another mechanism by which anti-VEGF treatment may predispose to arterial thrombosis relies in the possibility that monoclonal antibodies targeting VEGF can induce platelet aggregation, degranulation and thrombosis through complex formation with VEGF and activation of the platelet FcgammaRIIa receptor [86].

Platelets are an important in vivo source of VEGF, both in health [87] and cancer [88-90], and thrombin generation plays a central role being capable of activating platelets, thus causing VEGF release, and ECs, thus increasing their expression of VEGFR2 and proinflammatory cytokines (Fig. (3)) [91]. Moreover, activation of thrombin produces prothrombin fragment $1+2(\mathrm{~F} 1+2)$ that act to dampen the positive feedback effect of thrombin to help finely control the angiogenic response [92]. Disruption of these regulatory mechanisms is of utmost importance especially during cancer chemotherapy, since changes in serum VEGF usually coincide with drug-induced thrombocytopenia and the subsequent rebound of platelets might have an unwanted effect of tumor through chemotherapy-induced endothelial damage, platelet activation and further VEGF release, supporting regrowth of the tumor during the second half of the cycle [88]. To avoid the undesired effects of VEGF delivered by platelets, especially during their rebound, there might be a place for drugs preventing platelet activation and aggregation during platelet recovery, as already described in other clinical settings [93].

\section{Thromboembolic Events in Patients Treated with Anti- Angiogenic Drugs}

\section{Bevacizumab-Based Therapies}

The pivotal role of VEGF in cancer development and dissemination has begun to be elucidated since the late eighties. Several publications have demonstrated [94-96] that VEGF block can induce tumor shrinkage and prevent metastases. The next logical step has been to design specific VEGF pathway inhibitors to interfere with tumor angiogenesis. The first drug proved to have antineoplastic properties by selectively inhibiting VEGF function has been a humanized monoclonal immunoglobulin $\mathrm{G}$ targeting soluble VEGF-A (bevacizumab, Avastin ${ }^{\circledR}$ ).

Bevacizumab is currently approved in combination with fluoropyrimidine-based chemotherapy for the treatment of patients with metastatic colorectal cancer in both first and second-line regimens [97-101]. It is also approved for the first-line treatment of patients with metastatic breast cancer in combination with paclitaxel [102], of patients with metastatic non-squamous non-small cell lung cancer in addition to platinum-based chemotherapy [103, 104] and of patients with metastatic renal cell cancer in combination with interferon alfa-2a [105].

In the pivotal phase III trial of first-line metastatic colorectal cancer treatment, bevacizumab in combination with standard irinotecan/fluorouracil chemotherapy gave a $10 \%$ increase in tumor response rate and a significant lengthening of progression-free and overall survival times (4.4 and 4.7 


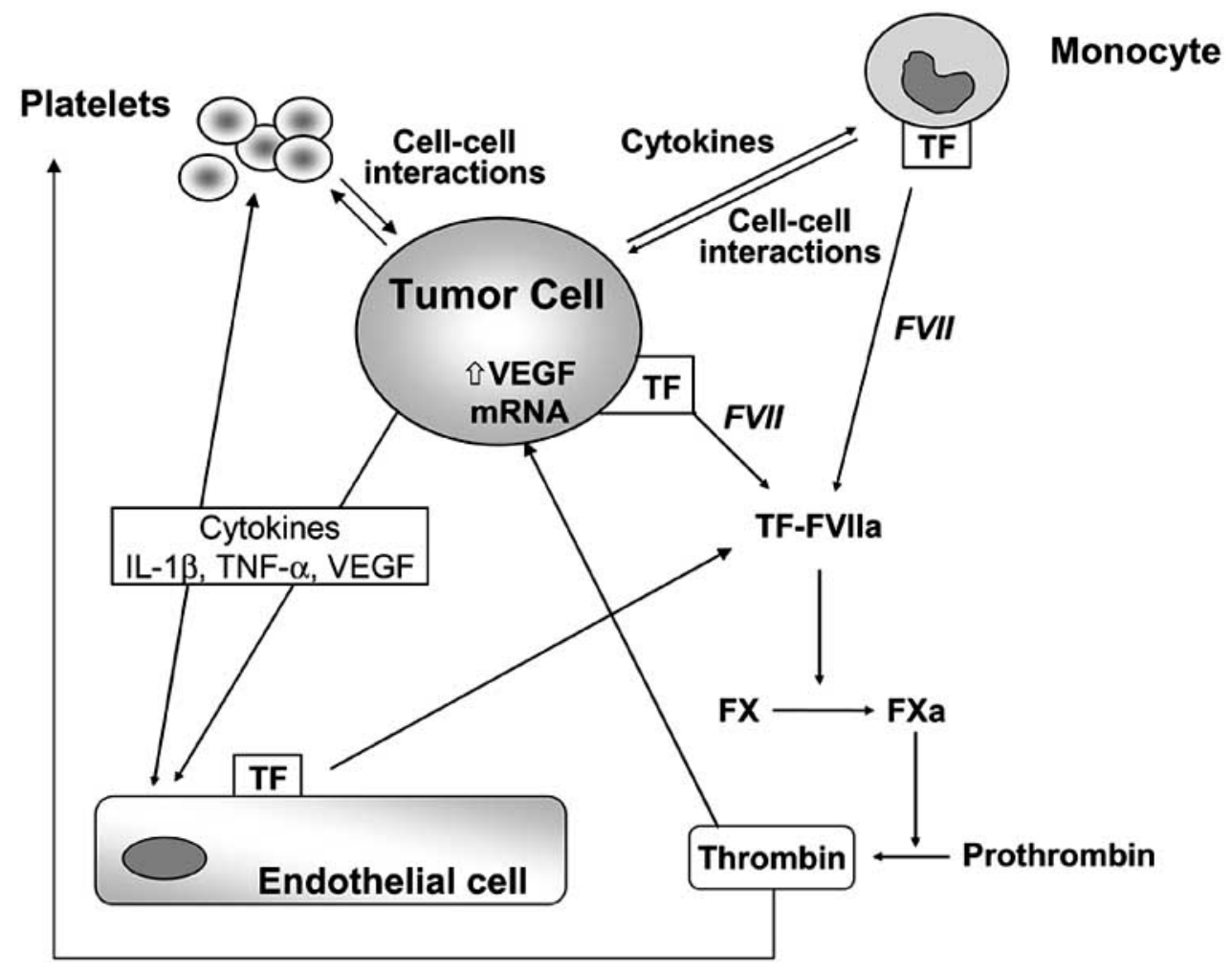

Fig. (3). Tumor cells may induce a procoagulant status either directly, through exposure of tissue factor (TF) or indirectly, through VEGF production and endothelial cell activation. Moreover, tumor cell and/or host cell produced cytokines [i.e., interleukin-1 $\beta$ (IL-1 $\beta$ ) or tumor necrosis factor- $\alpha(\mathrm{TNF}-\alpha)$ ] will sustain a pro-inflammatory, prothrombotic environment leading to further rounds of activation, release of platelet VEGF, or TF exposure and cytokine release by monocytes or tumor associated macrophages. Coagulation activation will ultimately lead to generation of thrombin, which may promote additional tumor VEGF mRNA induction.

month improvement, respectively, as median survival times) [97]. In this study, an increased incidence of thrombotic events was found in bevacizumab arm (393 patients) compared to the control arm (397 patients), but this was not significant (19.4\% vs. 16.2\%, respectively) [97].

Since the first approval for clinical use in metastatic colorectal cancer patients in 2004, bevacizumab has been proven effective in several cancer types other than colorectal, and its indications, as above-mentioned, have been broadened now to include renal, breast and lung cancer (www.fda.gov, www.emea.europa.eu).

Until now six large randomized phase III studies specifically exploring the advantage of adding bevacizumab to standard treatment have been fully published [97, 98, 104106], and data on thrombotic events have been reported for all the studies. The increased risk of thromboembolic events with bevacizumab use is now well-recognized (Table 1). However, except for the study by Hurwitz et al., their incidence remains relatively low with $P$ values not reaching significance.

To specifically address questions on bevacizumab-related thromboembolic risk, Genentech provided 2 subset analyses: the first has been recently published and refers to a retrospective pooled analysis of 5 randomized Genentech trials regarding different solid cancer types [107], the second one has been presented at the 2007 American Society of Clinical Oncology Annual Meeting and is a pre-planned analysis of the BRiTE study ${ }^{1}$, an observational cohort study involving 248 study sites in 49 states where bevacizumab had to be used as first line treatment for metastatic colorectal cancer patients in combination with a chemotherapy regimen chosen at investigator's discretion.

In the former study, adverse events analysis was performed on 1745 patients (782 treated with bevacizumab+chemotherapy, 963 with chemotherapy only) pooled from the phase III study by Hurwitz et al. [97] and from 4 other randomized phase II studies, 2 involving colorectal cancer patients [108, 109], 1 lung cancer patients [110] and 1 breast cancer patients [106]. Overall incidence of thrombotic events was calculated for the control and bevacizumab group and the possible impact of pre-existent risk factors for cardiovascular morbidity were evaluated. While no relevant differences were found for venous events (VTEs) between the 2 treatment groups, a nearly 2-fold increase of arterial thromboembolic events (ATEs) was demonstrated for patients receiving bevacizumab $(3.8 \%$ vs. $1.7 \%)$ with a Hazard Ratio (HR) of 2.0 (95\% CI 1.05-3.75, P=0.031) in favor of chemotherapy-only group. ATEs were considered as 1 of the following 7 events: angina pectoris, arterial thrombosis, cerebral infarct, cerebral ischemia, cerebrovascular accident, myocardial infarction or myocardial ischemia. When base-

\footnotetext{
${ }^{1}$ Sugrue MM. Serious arterial thromboembolic events (sATE) in patients (pts) with metastatic colorectal cancer (mCRC) treated with bevacizumab (BV): Results from the BRiTE registry. 2007 ASCO Annual Meeting. Abstract No: 4136.
} 
Table 1. Incidence of Thromboembolic Events in Randomized Phase III Studies

\begin{tabular}{|c|c|c|c|c|c|}
\hline Study & Regimen & No. of Patients & TE Incidence & VTE Incidence & ATE Incidence \\
\hline Hurwitz 2004 [98] & $\begin{array}{c}\text { IFL+BEV } \\
v s . \\
\text { IFL }\end{array}$ & $\begin{array}{l}402 \\
411\end{array}$ & $\begin{array}{l}19.4 \% \\
16.2 \%\end{array}$ & - & - \\
\hline Miller 2005 [107] & $\begin{array}{c}\text { Capecitabine/BEV } \\
\text { vs. } \\
\text { Capecitabine }\end{array}$ & $\begin{array}{l}229 \\
215\end{array}$ & $\begin{array}{l}7.4 \% \\
5.6 \%\end{array}$ & - & - \\
\hline Sandler 2006 [105] & $\begin{array}{c}\text { Carboplatin/Paclitaxel/BEV } \\
\text { vs. } \\
\text { Carboplatin/Paclitaxel }\end{array}$ & $\begin{array}{l}434 \\
444\end{array}$ & - & - & - \\
\hline Escudier 2007 [106] & $\begin{array}{c}\text { Interferon alfa-2a/BEV } \\
v s . \\
\text { Interferon alfa-2a }\end{array}$ & $\begin{array}{l}325 \\
316\end{array}$ & - & $\begin{array}{l}3 \% \\
1 \%\end{array}$ & $\begin{array}{l}1.5 \% \\
0.7 \%\end{array}$ \\
\hline Miller 2007 [103] & $\begin{array}{c}\text { Paclitaxel/BEV } \\
\text { vs. } \\
\text { Paclitaxel }\end{array}$ & $\begin{array}{l}365 \\
346\end{array}$ & $\begin{array}{l}2.2 \% \\
1.4 \%\end{array}$ & - & - \\
\hline Saltz 2008 [99] & $\begin{array}{c}\text { Oxaliplatin/fluoropirimidin/BEV } \\
\text { vs. } \\
\text { Oxaliplatin/fluoropirimidin }\end{array}$ & $\begin{array}{l}694 \\
675\end{array}$ & - & $\begin{array}{l}8 \% \\
5 \%\end{array}$ & $\begin{array}{l}2 \% \\
1 \%\end{array}$ \\
\hline
\end{tabular}

TE (any thromboembolic event), VTE (venous thromboembolic events), ATE (arterial thromboembolic events), BEV (bevacizumab), IFL: irinotecan/fluorouracil based chemotherapy.

line risk factors for thrombotic events (age, sex, hypertension, asymptomatic atherosclerosis, diabetes and history of arterial thromboembolism, myocardial infarction, stroke, transient ischemic attack, or venous thrombosis) were included in a multivariate analysis together with bevacizumab use, variables independently influencing the risk of ATEs remain bevacizumab use, age older than 65 years and history of other ATEs at study entry (HR $1.95 \mathrm{p}=0.04$, HR $2.17 \mathrm{p}=$ 0.01 , HR $3.65 \mathrm{p}<0.001$, respectively). Furthermore, the majority of ATEs occurred within 3 months of treatment [107].

Impact of aspirin use was also analyzed. Consumers of more than $325 \mathrm{mg} /$ day aspirin were excluded from the trial, while lower doses were allowed. In the pooled population only a minority of patients were taking low dose aspirin $(13 \%)$ and no significant differences in terms of ATEs were detected in this subset of patients between subjects receiving bevacizumab and subject treated with chemotherapy only, however the incidence was higher in the bevacizumab arm despite the use of a concomitant anti-thrombotic drug $(1.2 \%$ vs. $5.1 \%, \mathrm{p}=0.159)$ [107].

Of note the incidence of ATEs in the breast cancer trial was low and did not differ between control and bevacizumab arms (1 event per arm) [106]. However, the proportion of premenopausal women, a well-known low risk subpopulation for arterial cardiovascular diseases, and presence of other potentially protective hormonal factors were not specified in the analysis.

Similar results have been achieved in the "lesscontrolled" prospective BRiTE trial, where bevacizumab was prevalently given in combination with fluorouracil/ ox- aliplatin regimen (60.7\% of patients). In the ATEs analysis of BRiTE registry similar definitions of ATEs and baseline risk factors, respect to Genentech study, were applied, with small differences (addition of "hypercholesterolemia requiring medication" in risk factors).

In the BRiTE trial, unlike Genentech study and other prospective bevacizumab trials, patients with a recent history ( $<12$ months) of myocardial infarction (MI) and cerebrovascular accidents (CVA) were not excluded. Overall incidence of ATEs in BRiTE was $1.8 \%$, with the majority events being MI and CVA (74\%). Most ATEs occurred within the first 6 months of therapy. Multivariate risk factors analysis confirmed history of ATEs at study entry, together with ECOG performance status $\geq 1$, to be an independent risk factor of developing ATEs during study treatment with bevacizumab, with a HR of $2.46(\mathrm{p}=0.025)$.

The BEATrial ${ }^{2}$ was a similarly designed prospective observational study, conducted in Europe, that enrolled 1,915 patients from 40 countries for whom the most commonly used chemotherapy regimen in combination with bevacizumab was oxliplatin/fluoruracil-based (47\%). Final efficacy and safety data have recently been presented at the 2008 American Society of Clinical Oncology (ASCO) annual meeting. Reported incidence of ATEs was comparable to that of BRiTE registry $(1.3 \%)$.

As far as VTEs are concerned, a detailed analysis of their occurrence in patients pooled from the studies by Kabbi-

\footnotetext{
${ }^{2}$ Berry SR, Van Cutsem E, Kretzschmar A, et al. Final efficacy results for bevacizumab plus standard first-line chemotherapies in patients with metastatic colorectal cancer: First BEAT. 2008 ASCO Annual Meeting. Abstract No: 4025.
} 
navar et al. [109] and Hurwitz et al. [97] was presented at the 2004 ASCO Annual Meeting by Novotny et al ${ }^{3}$. Overall, no substantial differences were detected in VTEs rate between bevacizumab-containing and chemotherapy-only groups, with 74 VTEs in the 492 bevacizumab-treated patients and 74 VTEs in the 500 chemotherapy-only treated patients (15\% for both). Most recently, Nalluri et al. performed a systematic review and meta-analysis of published randomized controlled trials to assess the overall risk of VTEs associated with the use of bevacizumab [111]. A total of 7956 patients with a variety of advanced solid tumors from 15 randomized controlled trials were identified and included for analysis. The results obtained showed that patients treated with bevacizumab had a significantly increased VTEs risk with a RR of 1.33 (95\% CI, 1.13-1.56; P<0.001) compared with controls. The risk was significantly increased for both all grade and high-grade VTE. In addition, the risk was similarly increased for bevacizumab at low or high dose [111], leading the Authors to conclude that the so called low dose of bevacizumab may be already reaching the saturation level to induce thrombosis; alternatively, the difference between the high and low doses of bevacizumab in thrombogenesis may be too small to detect [111].

\section{Other Angiogenesis Inhibitors}

Additional angiogenesis inhibitors have recently been approved by the US and European drugs regulatory agencies (FDA and EMEA) for the treatment of solid and hematological malignancies (lenalidomide, thalidomide, sunitinib, sorafenib). All these agents inhibit VEGF signaling by blocking VEGF ligand or VEGF receptor functions and for some of them (e.g. sunitinib) an inhibition of other important tyrosine-kinase proteins, such as platelet-derived growth factor receptor (PDGFR), has been also demonstrated.

An increased incidence of ATEs has been also reported with the use of such inhibitors. Lenalidomide and thalidomide are immunomodulatory drugs, structurally related to each other, with pleiotropic activities, including antiangiogenic and antineoplastic properties. It has been observed a surprisingly higher incidence of VTEs in multiple myeloma patients treated with these drugs, but how much part can be attributable to their antiangiogenic activity remains unclear [112-114]. In a recently published pooled analysis by Menon et al. [115] with multiple myeloma patients enrolled in 3 distinct lenalidomide-based clinical trials, $8 \%$ of the 125 analyzed patients developed deep vein thrombosis despite the fact that half of them were taking primary thromboprophylactic therapy. There was a trend to a higher incidence of thrombosis in patients receiving concomitant high-dose corticosteroid therapy.

Sunitinib and sorafenib are 2 small molecules inhibiting the tyrosin-kinase activity of vascular endothelial growth factor receptor (VEGFR). Sunitinib has been proven effective in the treatment of gastrointestinal stromal tumors and renal cell carcinomas [116, 117], sorafenib provides significant improvement in progression-free survival in patients

\footnotetext{
${ }^{3}$ Novotny WF, Holmgren E, Nelson B, Mass R, Kabbinavar F, Hurwitz H. Bevacizumab (a monoclonal antibody to vascular endothelial growth factor) does not increase the incidence of venous thromboembolism when added to first-line chemotherapy to treat metastatic colorectal cancer. 2004 ASCO Annual Meeting. Abstract No: 2184.
}

with renal cell carcinoma [118] and hepatocellular carcinoma ${ }^{4}$. While thromboembolic events have not yet been specifically analyzed for the 2 drugs, a $3 \%$ incidence of VTEs for sunitinib and a $2.9 \%$ incidence of treatment-emergent cardiac ischemia/infarction events are reported in the respective European Public Assessment Reports (http://www.emea.europa.eu).

Although data with respect to incidence and management of cardiovascular and cerebrovascular events from bevacizumab are more mature than those from the various VEGFR tyrosine kinase inhibitors, it is conceivable that, considering the fact that the VEGF inhibitory effects of the various classes of angiogenesis inhibitors are comparable, the inherent risks for any such event is theoretically comparable. As a matter of fact, the apparent differences in incidence of any cardiovascular thromboembolic event observed between bevacizumab and small molecules may be related to the yet relatively small number of patients that have been exposed to the latter [119].

\section{CONCLUSIONS AND PERSPECTIVES}

The clinical use of bevacizumab is rapidly increasing and we have now sufficient experience and number of treated patients to draw reasonable conclusions on its toxic profile. The thrombogenic effect of the drug seems to be exerted mainly in arteries, with the risk of venous thrombotic events being comparable to that of patients treated with standard chemotherapy. Some unclear points remain on the definition and grading of VTE among different trials and rate of asymptomatic VTE may be underestimated ${ }^{5}$.

The incidence of ATEs attributable to bevacizumab remains low (2-3\%) but it is double in size respect to that observed in chemotherapy-only treated patients with a significant difference. However, increased risk of ATEs in bevacizumab-treated patients seems to be mainly related to age, history of previous ATE and ECOG performance status, variables that have to be taken into account before starting an antiangiogenic treatment.

Moreover, undetectable thrombotic phenomena of the microvasculature seem to have a role also on pathogenesis of other side effects typically associated with bevacizumab, such as hypertension and proteinuria $[120,121]$.

On the other hand, the protective role of other factors such as concomitant use of antihrombotic drugs and hormonal factors still has to be elucidated. Considering the significant impact of history of ATEs of new ATEs on bevacizumab treatment, exclusion of patients with recent episodes (within 12 months) of relevant cardiovascular events should be maintained in future bevacizumab-involving trials. The real impact of thromboembolic toxicity of other antiangiogenic agents such as sunitinib and sorafenib needs further investigations and larger study populations.

\footnotetext{
${ }^{4}$ Llovet J, Ricci S, Mazzaferro V, et al. Sorafenib improves survival in advanced Hepatocellular Carcinoma (HCC): Results of a Phase III randomized placebocontrolled trial (SHARP trial). 2007 ASCO Annual Meeting. Abstract No: LBA1.

${ }^{5}$ Suenaga M, Mizunuma N, Shinozaki E, et al. Doppler ultrasound imaging in management of venous thromboembolic events in patients treated with chemotherapy and bevacizumab. 2008 ASCO Gastrointestinal Cancers Symposium. Abstract No: 508.
} 
The critical issues emerging from the available studies are, firstly, how to best prevent these complications and, secondly, how to best manage the haemostatic complications of antiangiogenic agents in cancer patients, particularly those undergoing concurrent treatment with standard chemotherapy [79]. The American Society of Clinical Oncology's guidelines do not recommend routine prophylaxis in ambulatory cancer patients receiving chemotherapy with the exception of myeloma patients receiving thalidomide or lenalidomide because of potential bleeding and the relatively low incidence of VTEs in this setting [122]. However, the absolute risk of VTEs in patients treated with bevacizumab may be comparable and, thus, prophylaxis may be conducted accordingly $[79,111]$. Future studies, specifically designed to address this issue, are urgently required to better define the causal association of antiangiogenic drugs with haemostatic complications and to establish the best prophylactic strategy.

\section{REFERENCES}

[1] Cohen JD. Overview of physiology, vascular biology, and mechanisms of hypertension. J Manag Care Pharm 2007; 13: S6-8.

[2] Furchgott RF, Zawadzki JV. The obligatory role of endothelial cells in the relaxation of arterial smooth muscle by acetylcholine. Nature 1980; 288: 373-6.

[3] Thomas SR, Witting PK, Drummond GR. Redox control of endothelial function and dysfunction: molecular mechanisms and therapeutic opportunities. Antioxid Redox Signal 2008; 10: 1713-65.

[4] White CR, Brock TA, Chang LY, Crapo J, Briscoe P, Ku D, Bradley WA, et al. Superoxide and peroxynitrite in atherosclerosis. Proc Natl Acad Sci USA 1994; 91: 1044-8.

[5] Vasquez-Vivar J, Kalyanaraman B, Martasek P, Hogg N, Masters $\mathrm{BS}$, Karoui $\mathrm{H}$, et al. Superoxide generation by endothelial nitric oxide synthase: the influence of cofactors. Proc Natl Acad Sci USA 1998; 95: 9220-5.

[6] Ferroni P, Basili S, Davì G. Oxidant stress and platelet activation in hypercholesterolemia. Antiox. Redox Signal 2004; 6: 747-56.

[7] Sen CK, Packer L. Antioxidant and redox regulation of gene transcription. FASEB J 1996; 10: 709-20.

[8] Ushio-Fukai M, Alexander RW. Reactive oxygen species as mediators of angiogenesis signaling: role of NAD(P)H oxidase. Mol Cell Biochem 2004; 264: 85-97.

[9] Monte M, Davel LE, De Lustig S. Hydrogen peroxide is involved in lymphocyte activation mechanisms to induce angiogenesis. Eur $\mathbf{J}$ Cancer 1997; 33: 676-82.

[10] Stone JR, Collins T. The role of hydrogen peroxide in endothelial proliferative responses. Endothelium 2002; 9: 231-8.

[11] Qian Y, Luo J, Leonard SS, Harris GK, Millecchia L, Flynn DC, et $a l$. Hydrogen peroxide formation and actin filament reorganization by $\mathrm{Cdc} 42$ are essential for ethanol-induced in vitro angiogenesis. J Biol Chem 2003; 278: 16189-97.

[12] Ushio-Fukai M. Redox signaling in angiogenesis: role of NADPH oxidase. Cardiovasc Res 2006; 71: 226-35.

[13] Guadagni F, Ferroni P, Palmirotta R, Portarena I, Formica V, Roselli M. TNF/VEGF cross-talk in chronic inflammation-related cancer initiation and progression: an early target in anticancer therapeutic strategy. In Vivo 2007; 21: 147-61.

[14] Carmeliet P, Jain RK. Angiogenesis in cancer and other diseases. Nature 2000; 407: 249-57.

[15] Leung DW, Cachianes G, Kuang WJ, Goeddel DV, Ferrara N. Vascular endothelial growth factor is a secreted angiogenic mitogen. Science 1989; 246: 1306-9.

[16] Keck PJ, Hauser SD, Krivi G. Vascular permeability factor, an endothelial cell mitogen related to PDGF. Science 1989; 246: 1309-12.

[17] Roy H, Bhardwaj S, Yla-Herttuala S. Biology of vascular endothelial growth factors. FEBS Lett 2006; 580: 2879-87.

[18] Baldwin ME, Halford MM, Roufail S, Williams RA, Hibbs ML, Grail D, et al. Vascular endothelial growth factor D is dispensable for development of the lymphatic system. Mol Cell Biol 2005; 25 : 2441-9.
[19] Ferrara N, Gerber HP, LeCouter J. The biology of VEGF and its receptors. Nat Med 2003; 9: 669-76.

[20] Kowanetz M, Ferrara N. Vascular Endothelial Growth Factor Signaling Pathways: Therapeutic Perspective. Clin Cancer Res 2006 12: 5018-22.

[21] Castilla MA, Arroyo MV, Aceituno E, Aragoncillo P, GonzálezPacheco FR, Texeiro E, et al. Disruption of cadherin-related junctions triggers autocrine expression of vascular endothelial growth factor in bovine aortic endothelial cells: effects on cell proliferation and death resistance. Circ Res 1999; 85: 1132-8.

[22] Gerber HP, McMurtrey A, Kowalski J, Yan M, Keyt BA, Dixit V, et al. Vascular endothelial growth factor regulates endothelial cell survival through the phosphatidylinositol 3'-kinase/Akt signal transduction pathway. Requirement for Flk-1/KDR activation. J Biol Chem 1998; 273: 30336-43.

[23] González-Pacheco FR, Deudero JJP, Castellanos MC, Castilla MA, Alvarez-Arroyo MV, Yagüe S, et al. Mechanisms of endothelial response to oxidative aggression: protective role of autologous VEGF and induction of VEGFR2 by $\mathrm{H}_{2} \mathrm{O}_{2}$. Am $\mathrm{J}$ Physiol Heart Circ Physiol 2006; 291: H1395-401.

[24] Connolly DT, Olander JV, Heuvelman D, Nelson R, Monsell R, Siegel N, et al. Human vascular permeability factor. Isolation from U937 cells. J Biol Chem 1989; 264: 20017-24.

[25] Clauss M, Gerlach M, Gerlach H, Brett J, Wang F, Familletti PC, et al. Vascular permeability factor: a tumor-derived polypeptide that induces endothelial cell and monocyte procoagulant activity, and promotes monocyte migration. J Exp Med 1990; 172: 1535-45.

[26] Esser S, Wolburg K, Wolburg H, Breier G, Kurzchalia T, Risau W. Vascular endothelial growth factor induces endothelial fenestrations in vitro. J Cell Biol 1998; 140: 947-59.

[27] Roberts WG, Palade GE. Increased microvascular permeability and endothelial fenestrations induced by vascular endothelial growth factor. J Cell Sci 1995; 108: 2369-79.

[28] Mukherjee S, Tessema M, Wandinger-Ness A. Vesicular trafficking of tyrosine kinase receptors and associated proteins in the regulation of signaling and vascular function. Circ Res 2006; 98; 74356.

[29] Feng D, Nagy JA, Hipp J, Dvorak HF, Dvorak AM. Vesiculovacuolar organelles and the regulation of venule permeability to macromolecules by vascular permeability factor, histamine and serotonin. J Exp Med 1996; 183: 1981-6.

[30] Qu H, Nagy JA, Senger DR, Dvorak HF, Dvorak AM. Ultrastructural localization of vascular permeability factor / vascular endothelial growth factor (VPF/VEGF) to the abluminal plasma membrane and vesiculovacuolar organelles of tumor microvascular endothelium. J Histochem Cytochem 1995; 43: 381-9.

[31] Murohara T, Horowitz JR, Silver M, Tsurumi Y, Chen D, Sullivan A, et al. Vascular endothelial growth factor / vascular permeability factor enhances vascular permeability via nitric oxide and prostacyclin. Circulation 1998; 97: 99-107.

[32] Labrecque L, Royal I, Surprenant DS, Patterson C, Gingras D, Beliveau R. Regulation of vascular endothelial growth factor receptor-2 activity by caveolin-1 and plasma membrane cholesterol. Mol Biol Cell 2003; 14: 334-47.

[33] Cao S, Yao J, McCabe TJ, Yao Q, Katusic ZS, Sessa WC, et al. Direct interaction between endothelial nitric-oxide synthase and dynamin-2. Implications for nitric-oxide synthase function. J Biol Chem 2001; 276: 14249-56.

[34] Wu HM, Yuan Y, Zawieja DC, Tinsley J, Granger H. Role of phospholipase $\mathrm{C}$, protein kinase $\mathrm{C}$, and calcium in VEGF-induced venular hyperpermeability. Am J Physiol 1999; 276: H535-42.

[35] Dejana E. Endothelial adherens junctions: implications in the control of vascular permeability and angiogenesis. J Clin Invest 1996 98: 1949-53.

[36] Esser S, Lampugnani MG, Corada M, Dejana E, Risau W. Vascular endothelial growth factor induces VE-cadherin tyrosine phosphorylation in endothelial cells. J Cell Sci 1998; 111: 1853-65.

[37] Cohen A, Carbajal J, Schaeffer JR. VEGF stimulates tyrosine phosphorylation of $\beta$-catenin and small-pore endothelial barrier dysfunction. Am J Physiol 1999; 277: H2038-49.

[38] Staker S, Vitali A, Caesar C, Domagala T, Groenen LC, Nice E, et al. A mutant form of vascular endothelial growth factor (VEGF) that lacks VEGF receptor-2 activation retains the ability to induce vascular permeability. J Biol Chem 1999; 274: 34884-92. 
[39] Byrne AM, Bouchier-Hayes DJ, Harmey JH. Angiogenic and cell survival functions of Vascular Endothelial Growth Factor (VEGF). J Cell Mol Med 2005; 9: 777-94.

[40] Alon T, Hemo I, Itin A, Pe'er J, Stone J, Keshet E. Vascular endothelial growth factor acts as a survival factor for newly formed retinal vessels and has implications for retinopathy of prematurity. Nat Med 1995; 1: 1024-8.

[41] Thakker GD, Hajjar DP, Muller WA, Rosengart TK. The role of phosphatidylinositol 39-kinase in vascular endothelial growth factor signaling. J Biol Chem 1999; 274: 10002-7.

[42] Gerber H-P, Dixit V, Ferrara N. Vascular endothelial growth factor induces expression of the antiapoptotic proteins Bcl-2 and A1 in vascular endothelial cells. J Biol Chem 1998; 273: 13313-6.

[43] Tran J, Rak J, Sheehan C, LaCasse E, Korneluk RG, Kerbel RS. Marked induction of the IAP antiapoptotic proteins survivin and XIAP by VEGF in vascular endothelial cells. Biochem Biophys Res Commun 1999; 264: 781-8.

[44] Parenti A, Morbidelli L, Cui XL, Douglas JG, Hood JD, Granger $\mathrm{HJ}$, et al. Nitric oxide is an upstream signal of vascular endothelial growth factor-induced extracellular signal-regulated kinase $1 / 2$ activation in postcapillary endothelium. J Biol Chem 1998; 273: 42206.

[45] Pedram A, Razandi M, Levin ER. Extracellular signal-regulated protein kinase/Jun kinase cross-talk underlies vascular endothelial cell growth factor-induced endothelial cell proliferation. J Biol Chem 1998; 273: 26722-8.

[46] Kroll J, Waltenberger J. The vascular endothelial growth factor receptor KDR activates multiple signal transduction pathways in porcine aortic endothelial cells. J Biol Chem 1997; 272: 32521-7.

[47] Carmeliet P, Lampugnani MG, Moons L, Breviario F, Compernolle $\mathrm{V}$, Bono $\mathrm{F}$, et al. Targeted deficiency or cytosolic truncation of the VE-cadherin gene in mice impairs VEGF-mediated endothelial survival and angiogenesis. Cell 1999; 98: 147-57.

[48] Vestweber D. VE-cadherin: the major endothelial adhesion molecule controlling cellular junctions and blood vessel formation. Arterioscler Thromb Vasc Biol 2008; 28: 223-32.

[49] Banu N, Teichman J, Dunlap-Brown M, Villegas G, Tufro A. Semaphorin $3 \mathrm{C}$ regulates endothelial cell function by increasing integrin activity. FASEB J 2006; 20: E1520-7.

[50] Shizukuda Y, Tang S, Yokota R, Ware A. Vascular endothelial growth factor induced endothelial cell migration and proliferation depend on a nitric oxide-mediated decrease in protein kinase $\mathrm{C} \delta$ activity. Circ Res 1999; 85: 247-56.

[51] Watanabe K, Hasegawa Y, Yamashita H, Shimizu K, Ding Y, Abe $\mathrm{M}$, et al. Vasohibin as an endothelium-derived negative feedback regulator of angiogenesis. J Clin Invest 2004; 114: 898-907.

[52] Sato Y, Sonoda H. The vasohibin family: a negative regulatory system of angiogenesis genetically programmed in endothelial cells. Arterioscler Thromb Vasc Biol 2007; 27: 37-41.

[53] Abedi H, Zachary I. Vascular endothelial growth factor stimulates tyrosine phosphorylation and recruitment to new focal adhesions of focal adhesion kinase and paxillin in endothelial cells. J Biol Chem 1997; 272: 15442-51.

[54] Rousseau S, Houle F, Kotanides H, Witte L, Waltenberger J, Landry J, et al. Vascular endothelial growth factor (VEGF)-driven actin-based motility is mediated by VEGFR2 and requires concerted activation of stress-activated protein kinase 2 (SAPK2/p38) and geldanamycin-sensitive phosphorylation of focal adhesion kinase. J Biol Chem 2000; 275: 10661-72.

[55] Wu LW, Mayo LD, Dunbar JD, Kessler KM, Baerwald MR, Jaffe $\mathrm{EA}$, et al. Utilization of distinct signaling pathways by receptors for vascular endothelial growth factor and other mitogens in the induction of endothelial cell proliferation. J Biol Chem 2000; 275: 5096103.

[56] Qi JH, Claesson-Welsh L. VEGF-induced activation of phosphoinositide 3-kinase is dependent on focal adhesion kinase. Exp Cell Res 2001; 263: 173-82.

[57] Rousseau S, Houle F, Landry J, Huot J. p38 MAP kinase activation by vascular endothelial growth factor mediates actin reorganization and cell migration in human endothelial cells. Oncogene 1997; 15: 2169-77.

[58] Gille H, Kowalski J, Li B, LeCouter J, Moffat B, Zioncheck TF, et al. Analysis of biological effects and signaling properties of Flt-1 (VEGFR-1) and KDR (VEGFR-2). A reassessment using novel receptor-specific vascular endothelial growth factor mutants. J Biol Chem 2001; 276: 3222-30.
[59] Lamoreaux WJ, Fitzgerald ME, Reiner A, Hasty KA, Charles S. Vascular endothelial growth factor increases release of gelatinase A and decreases release of tissue inhibitor of metalloproteinases by microvascular endothelial cells in vitro. Microvasc Res 1998; 55: 29-42.

[60] Noiri E, Hu Y, Bahou WF, Keese CR, Giaever I, Goligorsky MS. Permissive role of nitric oxide in endothelin-induced migration of endothelial cells. J Biol Chem 1997; 272: 1747-52.

[61] Goligorsky MS, Abedi H, Noiri E, Takhtajan A, Lense S, Romanov $\mathrm{V}$, et al. Nitric oxide modulation of focal adhesions in endothelial cells. Am J Physiol 1999; 276: C1271-81.

[62] Ziche M, Morbidelli L, Choudhuri R, Zhang HT, Donnini S, Granger HJ, et al. Nitric oxide synthase lies downstream from vascular endothelial growth factor-induced but not basic fibroblast growth factor-induced angiogenesis. J Clin Invest 1997; 99: 262534.

[63] Papapetropoulos A, Garcia-Gardena G, Madri J, Sessa W. Nitric oxide production contributes to the angiogenic properties of vascular endothelial growth factor in human endothelial cells. J Clin Invest 1997; 100: 3131-9.

[64] Dimmeler S, Dernbach E, Zeiher AM. Phosphorylation of the endothelial nitric oxide synthase at Ser-1177 is required for VEGFinduced endothelial cell migration. FEBS Lett 2000; 477: 258-62.

[65] Wheeler-Jones C, Abu-Ghazaleh R, Cospedal R, Houliston RA, Martin J, Zachary I. Vascular endothelial growth factor stimulates prostacyclin production and activation of cytosolic phospholipase $\mathrm{A}_{2}$ in endothelial cells via $\mathrm{p} 42 / \mathrm{p} 44$ mitogen activated protein kinases. FEBS Lett 1997; 420: 28-32.

[66] Ku DD, Zaleski JK, Liu S, Brock TA. Vascular endothelial growth factor induces EDRF-dependent relaxation in coronary arteries. Am J Physiol 1993; 265: H586-92.

[67] Laitinen M, Zachary I, Breier G, Pakkanen T, Häkkinen T, Luoma $\mathrm{J}$, et al. VEGF gene transfer reduces intimal thickening via increased production of nitric oxide in carotid arteries. Hum Gene Ther 1997; 8: 1737-44.

[68] van der Zee R, Murohara T, Luo Z, Zollmann F, Passeri J, Lekuta $\mathrm{C}$, et al. Vascular endothelial growth factor / vascular permeability factor augments nitric oxide release from quiescent rabbit and human vascular endothelium. Circulation 1997; 95: 1030-7.

[69] Tsurumi Y, Murohara T, Krasinski K, Chen D, Witzenbichler B, Kearney M, et al. Reciprocal relation between VEGF and NO in the regulation of endothelial integrity. Nat Med 1997; 3: 879-86.

[70] Gliki G, Abu-Ghazaleh R, Jezequel S, Wheeler-Jones C, Zachary I. Vascular endothelial growth factor-induced prostacyclin production is mediated by a protein kinase $\mathrm{C}$ (PKC)-dependent activation extracellular signal-regulated protein kinases 1 and 2 involving PKC$\delta$ and by mobilization of intracellular $\mathrm{Ca}^{2+}$. Biochem $\mathrm{J} 2001 ; 353$ : 503-12.

[71] Zachary I, Gliki G. Signaling transduction mechanisms mediating biological actions of the vascular endothelial growth factor family. Cardiovasc Res 2001; 49: 568-81.

[72] Shen B-Q, Lee DY, Zioncheck TF. Vascular endothelial growth factor governs endothelial nitric-oxide synthase expression via a KDR/ Flk-1 receptor and protein kinase $\mathrm{C}$ signaling pathway. J Biol Chem 1999; 274: 33057-63.

[73] Bouloumié A, Schini-Kerth V, Busse R. Vascular endothelial growth factor up-regulates nitric oxide synthase expression in endothelial cells. Cardiovasc Res 1999; 41: 773-80.

[74] Hood JD, Meininger CJ, Ziche M, Granger HJ. VEGF upregulates ecNOS message, protein, and NO production in human endothelial cells. Am J Physiol 1998; 274: 1054-8.

[75] Khurana R, Simons M, Martin JF, Zachary IC. Role of Angiogenesis in Cardiovascular Disease: A Critical Appraisal. Circulation 2005; 112: 1813-24.

[76] Ferroni P, Roselli M, Guadagni F, Martini F, Mariotti S, Marchitelli E, et al. Biological effects of a software-controlled voltage pulse generator (PhyBack PBK-2C) on the release of vascular endothelial growth factor (VEGF). In Vivo 2005; 19: 949-58.

[77] Pepper MS, Ferrara N, Orci L, Montesano R. Vascular endothelial growth factor (VEGF) induces plasminogen activators and plasminogen activator inhibitor-1 in microvascular endothelial cells. Biochem Biophys Res Commun 1991; 181: 902-6.

[78] Brock TA, Dvorak HF, Senger DR. Tumor-secreted vascular permeability factor increases cytosolic $\mathrm{Ca} 2+$ and von Willebrand factor release in human endothelial cells. Am J Pathol 1991; 138: 213 21. 
[79] Elice F, Jacoub J, Rickles FR, Falanga A, Rodeghiero F. Hemostatic complications of angiogenesis inhibitors in cancer patients. Am J Hematol 2008; 83: 862-70.

[80] Daher IN, Yeh ET. Vascular complications of selected cancer therapies. Nat Clin Pract Cardiovasc Med. 2008; 5: 797-805.

[81] Chen Y, Jungsuwadee P, Vore M, Butterfield DA, St Clair DK. Collateral damage in cancer chemotherapy: oxidative stress in non targeted tissues. Mol Interv 2007; 7: 147-56.

[82] Conklin KA. Chemotherapy-associated oxidative stress: impact on chemotherapeutic effectiveness. Integr Cancer Ther 2004; 3: 294300 .

[83] Pignatelli P, Properzi E, Pisani M, Clerico A, Schiavetti A, Lenti L, et al. Effects on platelet function by combination etoposide and carboplatin chemotherapy in pediatric oncologic patients. Platelets 1998; 9: 309-14

[84] Kamba T, McDonald DM. Mechanisms of adverse effects of antiVEGF therapy for cancer. British Journal of Cancer 2007; 96: 1788-95.

[85] Kilickap S, Abali H, Celik I. Bevacizumab, bleeding, thrombosis, and warfarin. J Clin Oncol 2003; 21: 3542.

[86] Meyer T, Robles-Carrillo L, Robson T, Langer F, Desai H, Davila $\mathrm{M}$, et al. Bevacizumab immune complexes activate platelets and induce thrombosis in FCGR2A transgenic mice. J Thromb Haemost. 2008 Oct 30. [Epub ahead of print]

[87] Martini F, Riondino S, Basili S, Bertazzoni G, Ferroni P. In vivo platelet activation is associated to increased plasma levels of vascular endothelial growth factor. J Thromb Haemost 2003; 1: 853-4.

[88] Verheul HM, Hoekman K, Luykx-de Bakker S, Eekman CA, Folman CC, Broxterman HJ, et al. Platelet: transporter of vascular endothelial growth factor. Clin Cancer Res 1997; 3: 2187-90.

[89] Banks RE, Forbes MA, Kinsey SE, Stanley A, Ingham E, Walters $\mathrm{C}$, et al. Release of the angiogenic cytokine vascular endothelial growth factor (VEGF) from platelets: significance for VEGF measurements and cancer biology. Br J Cancer 1998; 77: 956-64.

[90] Roselli M, Mineo TC, Basili S, Mariotti S, Martini F, Bellotti A, et al. Vascular Endothelial Growth Factor (VEGF-A) Plasma Levels in Non-Small Cell Lung Cancer. Relationship with Coagulation and Platelet Activation Markers. Thromb Haemost 2003; 89: 177 84

[91] Tsopanoglou N, Maragoudakis ME. On the mechanism of thrombin induced angiogenesis: potentiation of VEGF activity on endothelial cells by upregulation of its receptors. J Biol Chem 1999; 274: 23969-76.

[92] Rhim TY, Park CS, Kirn E, Kim SS. Human prothrombin fragment 1 and 2 inhibit $\beta$ FGF-induced BCE cell growth. Biochem Biophys Res Commun 1998; 252: 513-6.

[93] Ferroni P, Martini F, D’Alessandro R, Magnapera A, Raparelli V, Scarno A, et al. In vivo platelet activation is responsible for enhanced Vascular Endothelial Growth Factor levels in hypertensive patients. Clin Chim Acta 2008; 388: 33-7.

[94] Ferrara N. Molecular and biological properties of vascular endothelial growth factor. J Mol Med 1999; 77:527-43.

[95] Kim KJ, Li B, Winer J, Armanini M, Gillett N, Phillips HS, et al. Inhibition of vascular endothelial growth factor-induced angiogenesis suppresses tumour growth in vivo. Nature 1993; 362: 8414.

[96] Borgstrom P, Bourdon MA, Hillan KJ, Sriramarao P, Ferrara N. Neutralizing antivascular endothelial growth factor antibody completely inhibits angiogenesis and growth of human prostate carcinoma micro tumors in vivo. Prostate 1998; 35: 1-10.

[97] Hurwitz H, Fehrenbacher L, Novotny W, Cartwright T, Hainsworth $\mathrm{J}$, Heim W, et al. Bevacizumab plus irinotecan, fluorouracil, and leucovorin for metastatic colorectal cancer. N Engl J Med 2004; 350: $2335-42$

[98] Saltz LB, Clarke S, Díaz-Rubio E, Scheithauer W, Figer A, Wong $\mathrm{R}$, et al. Bevacizumab in combination with oxaliplatin-based chemotherapy as first-line therapy in metastatic colorectal cancer: a randomized phase III study. J Clin Oncol 2008; 26: 2013-9.

[99] Fuchs CS, Marshall J, Mitchell E, Wierzbicki R, Ganju V, Jeffery $\mathrm{M}$, et al. Randomized, controlled trial of irinotecan plus infusional, bolus, or oral fluoropyrimidines in first-line treatment of metastatic colorectal cancer: results from the BICC-C Study. J Clin Oncol 2007; 25: 4779-86.

[100] Giantonio BJ, Catalano PJ, Meropol NJ, O'Dwyer PJ, Mitchell EP, Alberts SR, et al. Bevacizumab in combination with oxaliplatin, fluorouracil, and leucovorin (FOLFOX4) for previously treated me- tastatic colorectal cancer: results from the Eastern Cooperative Oncology Group Study E3200. J Clin Oncol 2007; 25: 1539-44.

[101] Cohen MH, Gootenberg J, Keegan P, Pazdur R. FDA Drug Approval Summary: Bevacizumab Plus FOLFOX4 as Second-Line Treatment of Colorectal Cancer. The Oncologist 2007; 12: 356-61.

[102] Miller K, Wang M, Gralow J, Dickler M, Cobleigh M, Perez EA, et al. Paclitaxel plus bevacizumab vs. paclitaxel alone for metastatic breast cancer. N Engl J Med 2007; 357: 2666-76.

[103] Cohen MH, Gootenberg J, Keegan P, Pazdur R. FDA Drug Approval Summary: Bevacizumab (Avastin ${ }^{\circledR}$ ) Plus Carboplatin and Paclitaxel as First-Line Treatment of Advanced/Metastatic Recurrent Nonsquamous Non-Small Cell Lung Cancer. The Oncologist 2007; 12: 713-8.

[104] Sandler A, Gray R, Perry MC, Brahmer J, Schiller JH, Dowlati A, et al. Paclitaxel-carboplatin alone or with bevacizumab for nonsmall-cell lung cancer. N Engl J Med 2006; 355: 2542-50.

[105] Escudier B, Pluzanska A, Koralewski P, Ravaud A, Bracarda S, Szczylik C, et al. Bevacizumab plus interferon alfa-2a for treatmen of metastatic renal cell carcinoma: a randomised, double-blind phase III trial. Lancet 2007; 370: 2103-11.

[106] Miller KD, Chap LI, Holmes FA, Cobleigh MA, Marcom PK, Fehrenbacher L, et al. Randomized phase III trial of capecitabine compared with bevacizumab plus capecitabine in patients with previously treated metastatic breast cancer. J Clin Oncol 2005; 23 792-9.

[107] Scappaticci FA, Skillings JR, Holden SN, Gerber HP, Miller K, Kabbinavar F, et al. Arterial thromboembolic events in patient with metastatic carcinoma treated with chemotherapy and bevacizumab. J Natl Cancer Inst 2007; 99: 1232-9.

[108] Kabbinavar F, Hurwitz HI, Fehrenbacher L, Meropol NJ, Novotny WF, Lieberman G, et al. Phase II, randomized trial comparing bevacizumab plus fluorouracil (FU)/leucovorin (LV) with FU/LV alone in patients with metastatic colorectal cancer. J Clin Oncol 2003; $21: 60-5$

[109] Kabbinavar FF, Schulz J , McCleod M, Patel T, Hamm JT, Hecht $\mathrm{JR}$, et al. Addition of bevacizumab to bolus fluorouracil and leucovorin in first-line metastatic colorectal cancer: results of a randomized phase II trial. J Clin Oncol 2005; 23: 3697-705.

[110] Johnson DH, Fehrenbacher L, Novotny WF, Herbst RS, Nemunaitis JJ, Jablons DM, et al. Randomized phase II trial comparing bevacizumab plus carboplatin and paclitaxel with carboplatin and paclitaxel alone in previously untreated locally advanced or metastatic non-small-cell lung cancer. J Clin Oncol 2004; 22: 2184 91

[111] Nalluri SR, Chu D, Keresztes R, Zhu X, Wu S. Risk of Venous Thromboembolism With the Angiogenesis Inhibitor Bevacizumab in Cancer Patients. A Meta-analysis. JAMA 2008; 300: 2277-85.

[112] Hirsh J. Risk of thrombosis with lenalidomide and its prevention with aspirin. Chest 2007; 131: 275-7.

[113] Palumbo A, Rajkumar SV, Dimopoulos MA, Richardson PG, San Miguel J, Barlogie B, et al. Prevention of thalidomide- and lenalidomide-associated thrombosis in myeloma. Leukemia 2008; 22: 414-23.

[114] Gieseler F. Pathophysiological considerations to thrombophilia in the treatment of multiple myeloma with thalidomide and derivates. Thromb Haemost 2008; 99: 1001-7.

[115] Menon SP, Rajkumar SV, Lacy M, Falco P, Palumbo A. Thromboembolic events with lenalidomide-based therapy for multiple myeloma. Cancer 2008; 112: 1522-8.

[116] Motzer RJ, Hutson TE, Tomczak P, Michaelson MD, Bukowski $\mathrm{RM}$, Rixe O, et al. Sunitinib vs. interferon alfa in metastatic renalcell carcinoma. N Engl J Med 2007; 356: 115-24.

[117] Demetri GD, van Oosterom AT, Garrett CR, Blackstein ME, Shah $\mathrm{MH}$, Verweij J, et al. Efficacy and safety of sunitinib in patients with advanced gastrointestinal stromal tumour after failure of imatinib: a randomised controlled trial. Lancet 2006; 368: 1329-38.

[118] Escudier B, Eisen T, Stadler WM, Szczylik C, Oudard S, Siebels $\mathrm{M}$, et al. Sorafenib in advanced clear-cell renal-cell carcinoma. N Engl J Med 2007; 356: 125-34.

[119] Eskens FA, Verweij J. The clinical toxicity profile of vascular endothelial growth factor (VEGF) and vascular endothelial growth factor receptor (VEGFR) targeting angiogenesis inhibitors; A review. Eur J Cancer 2006; 42: 3127-39.

[120] Mourad JJ, des Guetz G, Debbabi H, Levy BI. Blood pressure rise following angiogenesis inhibition by bevacizumab. A crucial role for microcirculation. Ann Oncol 2008; 19: 927-34. 
[121] Eremina V, Jefferson JA, Kowalewska J, Hochster H, Haas M, Weisstuch $\mathrm{J}$, et al. VEGF inhibition and renal thrombotic microangiopathy. N Engl J Med 2008; 358: 1129-36.

[122] Lyman GH, Khorana AA, Falanga A, Clarke-Pearson D, Flowers C, Jahanzeb M, et al. American Society of Clinical Oncology guideline: recommendations for venous thromboembolism prophylaxis and treatment in patients with cancer. J Clin Oncol 2007; 25: 5490-505. 